Check for updates

Cite this: Mater. Chem. Front. 2019, 3, 2066

Received 31st May 2019,

Accepted 24th July 2019

DOI: $10.1039 / c 9 q m 00358 d$

rsc.li/frontiers-materials

\section{Tunable aggregation-induced circularly polarized luminescence of chiral AIEgens via the regulation of mono-/di-substituents of molecules or nanostructures of self-assemblies $\dagger$}

\author{
Shuwei Zhang, (D) *a Jie Fan, ${ }^{a}$ Yuxiang Wang, ${ }^{b}$ Dong Li, ${ }^{a}$ Xiaodong Jia, (D) ${ }^{a}$ Yu Yuan ${ }^{a}$ \\ and Yixiang Cheng (D)*b
}

Four chiral AlE-active luminogens (AlEgens) containing tetraphenylethene (TPE) and one or two chiral glutamic moieties connected by thiourea were designed and synthesized. All AlEgens showed tunable aggregation-induced circularly polarized luminescence (AICPL) by adjusting the mono-/di-substituents of molecules or nanostructures of self-assemblies. The enantiotopic mono-substituted compounds (TPE-Glu) exhibited mirror-imaged AICPL signals with the maximal $\left|g_{\text {lum }}\right|$ value of up to 0.02 . Interestingly, the di-substituted cis- and trans-isomers showed reverse AICPL signals compared with those of monosubstituted ones. cis- and trans-isomers (TPE-DGlu) showed similar AICPL properties, whose signs of AICPL signals reversed while the water fraction $\left(f_{w}\right)$ was more than $80 \%$. The SEM images of their selfassemblies indicated that the AICPL properties should have an intrinsic relation with their molecular structures or self-assembled nanostructures.

\section{Introduction}

Circularly polarized luminescence (CPL) refers to the phenomenon that chiral luminescent substances emit different ratios of left and right circularly polarized light, which has been attracting increasing attention due to its special properties and potential applications in various fields such as the investigation of the excited chiral molecular structures, 3D optical displays, information storage and processing, molecular switches, biological detection and probing. ${ }^{1}$ Up to now, different CPL systems have been reported, such as chiral organic conjugated molecules, polymers, organogels, and lanthanide complexes. ${ }^{2}$ However, most conventional organic conjugated materials suffer from aggregation-caused quenching (ACQ) effect in the solid state, which greatly limits their applications in optics. ${ }^{3}$ In 2001 , Tang et al. first proposed aggregation-induced emission (AIE), which is used to describe the phenomenon that substances exhibit non-emissive behavior in a solution but have strong emission in the aggregated state. ${ }^{4}$ Therefore, the AIE property provides an approach to prepare CPL materials with high emission intensity in the solid state.

\footnotetext{
${ }^{a}$ School of Chemistry and Chemical Engineering, Yangzhou University, Yangzhou, 225002, P. R. China. E-mail: shuweiz@yzu.edu.cn

${ }^{b}$ Key Lab of Mesoscopic Chemistry of MOE and Collaborative Innovation Center of Chemistry for Life Sciences, School of Chemistry and Chemical Engineering, Nanjing University, Nanjing 210023, P. R. China. E-mail: yxcheng@nju.edu.cn $\dagger$ Electronic supplementary information (ESI) available. See DOI: 10.1039/ c9qm00358d
}

Tang et al. originally combined AIE and CPL and prepared a compound by introducing chiral D-mannose moiety into an AIE-active silole in 2012, which exhibited no CPL signal in solution but high AICPL signal in the aggregated state. ${ }^{5}$ Since then, some other AIE-active CPL materials have been reported in different research fields. ${ }^{6}$ Among them, supramolecular assemblies formed through non-covalent interactions have received considerable attention because the chiral assemblies usually possess better CPL properties than those of chiral molecules and could transfer CPL-silence molecular chirality to CPL-on chiral nanostructures. ${ }^{7}$

It is well-known that molecular chirality has great influence on the optical activity of chiral compounds. ${ }^{8}$ However, the impact of $c i s$ - and trans-isomers on the optical activity of chiral molecules, particularly for the CPL property has rarely been studied. ${ }^{9}$ Although several studies have reported the influence of nanostructures on the AICPL property, it is still valuable to design chiral supramolecular systems that could be effectively regulated to obtain chiral materials with a tunable AICPL property. $^{10}$

Herein, we designed and synthesized four compounds, which contained AIE-active tetraphenylethene (TPE) and one or two chiral glutamic moieties connected by thiourea. The enantiotopic mono-substituent compounds are labelled as TPE-L-Glu and TPE-D-Glu, while the di-substituent cis- and transisomers are marked as cis-TPE-L-DGlu and trans-TPE-L-DGlu, respectively. Both mono- and di-substituted compounds exhibited 


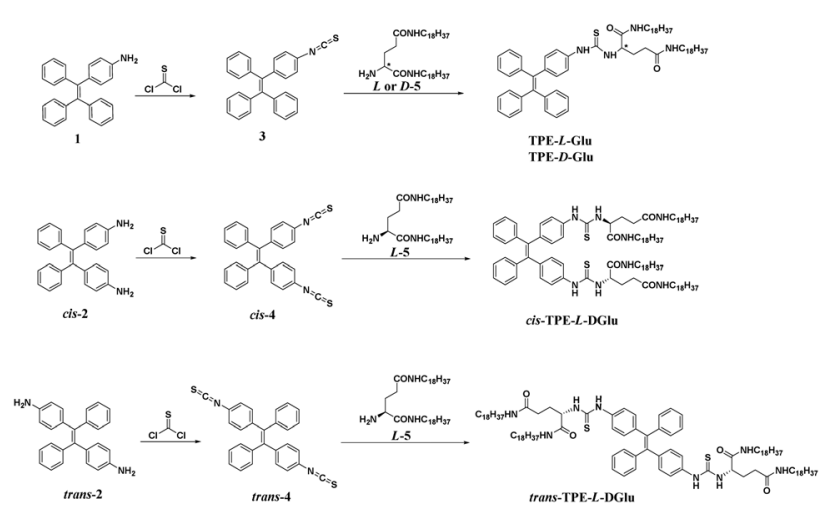

Scheme 1 Synthetic procedures for the preparation of TPE-L-Glu, TPE-D-Glu, cis-TPE-L-DGlu and trans-TPE-L-DGlu.

very weak emission and optical activity in THF, but showed obviously increasing fluorescence and tunable aggregationinduced circular dichroism (CD) and circularly polarized luminescence (CPL) signals with the addition of water, which demonstrated typical AIE and AICPL properties. The enantiotopic monosubstituted compounds (TPE-Glu) exhibited mirror-imaged AICPL signals, and the $\left|g_{\text {lum }}\right|$ value could reach 0.02 when water fraction $\left(f_{\mathrm{w}}\right)$ was at $50 \%$. However, the di-substituted cis- and trans-isomers showed reverse AICPL signals compared with mono-substituted ones even when the same chiral glutamic moiety was used. cis-TPE-L-DGlu and trans-TPE-L-DGlu displayed similar optically active properties, whose aggregation-induced CD and CPL signals in more than $80 \% f_{\mathrm{w}}$ mixed solvents was very different from those in less than $80 \% f_{\mathrm{w}}$ mixed solvents. The SEM images of their self-assemblies indicated that AICPL properties could be related to both molecular structures and microstructures of the formed nanostructures (Scheme 1).

\section{Experimental}

\section{Preparation of compound 3}

A mixture of compound $1(0.50 \mathrm{~g}, 1.44 \mathrm{mmol})$ and triethylamine (0.6 mL, $4.32 \mathrm{mmol}$ ) was dissolved in $15 \mathrm{~mL}$ dichloromethane, followed by the addition of thiophosgene $(0.15 \mathrm{~mL}, 1.96 \mathrm{mmol})$ in an ice bath. The reaction mixture was stirred for $4 \mathrm{~h}$ at ambient temperature. Then, $30 \mathrm{~mL}$ dichloromethane was added, and the mixture was washed with water and saturated brine, and then dried over anhydrous $\mathrm{Na}_{2} \mathrm{SO}_{4}$. After the solvent was removed under reduced pressure to obtain the residue, which was purified by silica gel column chromatography (hexane/ ethyl acetate, 20/1, v/v) compound 3 was obtained as a yellow oil (0.49 g, 87\%). ${ }^{1} \mathrm{H}$ NMR (400 MHz, $\left.\mathrm{CDCl}_{3}\right) \delta$ (ppm): 6.95 (d, $J=7.1 \mathrm{~Hz}, 2 \mathrm{H}), 7.00(\mathrm{~d}, J=4.2 \mathrm{~Hz}, 7 \mathrm{H}), 7.13-7.10(\mathrm{~m}, 10 \mathrm{H})$. HRMS $\left(\mathrm{ESI}^{+}\right): m / z$ calcd $\left[\mathrm{M}^{+}\right]$389.1238; found 389.1316.

\section{Preparation of cis-4 and trans-4}

The same procedure as that of compound 3 was followed for cis-4 and trans-4. The characterization of cis-4: ${ }^{1} \mathrm{H}$ NMR $(400 \mathrm{MHz}$, $\left.\mathrm{CDCl}_{3}\right) \delta(\mathrm{ppm}): 6.93(\mathrm{~d}, J=8.7 \mathrm{~Hz}, 6 \mathrm{H}), 6.96(\mathrm{~d}, J=9.4 \mathrm{~Hz}, 8 \mathrm{H})$, $7.14(\mathrm{~s}, 4 \mathrm{H})$. HRMS (MALDI-TOF): $m / z$ calcd $\left[\mathrm{M}^{+}\right]$446.0911; found
446.0945. The characterization of trans-4: ${ }^{1} \mathrm{H}$ NMR $(400 \mathrm{MHz}$, $\left.\mathrm{CDCl}_{3}\right) \delta(\mathrm{ppm}): 6.95(\mathrm{~d}, J=7.1 \mathrm{~Hz}, 2 \mathrm{H}), 7.00(\mathrm{~d}, J=4.2 \mathrm{~Hz}, 6 \mathrm{H})$, $7.11(\mathrm{dd}, J=8.2,2.5 \mathrm{~Hz}, 10 \mathrm{H})$. HRMS (MALDI-TOF): $m / z$ calcd $\left[\mathrm{M}^{+}\right]$ 446.0911; found 446.0952.

\section{Preparation of TPE-L-Glu and TPE-D-Glu}

A mixture of compound $3(0.50 \mathrm{~g}, 1.28 \mathrm{mmol})$ and compound L-5 (1.67 g, $2.57 \mathrm{mmol})$ was dissolved in $30 \mathrm{~mL}$ of anhydrous THF. The reaction mixture was stirred for $4 \mathrm{~h}$ at $80{ }^{\circ} \mathrm{C}$. After cooling to room temperature, the reaction mixture was concentrated to afford the residue, which was purified via silica gel column chromatography $\left(\mathrm{CH}_{2} \mathrm{Cl}_{2} / \mathrm{MeOH}, 20 / 1, \mathrm{v} / \mathrm{v}\right)$ to afford TPE-L-Glu as a pale-white powder (1.05 g, 77\%). ${ }^{1} \mathrm{H}$ NMR $\left(400 \mathrm{MHz}, \mathrm{CDCl}_{3}\right) \delta(\mathrm{ppm}): 0.86(\mathrm{t}, J=6.6 \mathrm{~Hz}, 6 \mathrm{H}), 1.24(\mathrm{~s}$, $60 \mathrm{H}), 1.48-1.49$ (m, 4H), 3.17-3.26 (m, 7H), 6.98-7.09 (m, 19H). HRMS (MALDI-TOF): $m / z$ calcd $\left[\mathrm{M}+\mathrm{Na}^{+}\right]$1061.7621; found 1061.7787. The prepared procedure of TPE-D-Glu was same as that for TPE-L-Glu. ${ }^{1} \mathrm{H}$ NMR (400 $\left.\mathrm{MHz}, \mathrm{CDCl}_{3}\right) \delta$ (ppm): 0.81 $(\mathrm{t}, J=6.0 \mathrm{~Hz}, 6 \mathrm{H}), 1.18(\mathrm{~s}, 60 \mathrm{H}), 1.44(\mathrm{~d}, J=5.9 \mathrm{~Hz}, 4 \mathrm{H}), 3.12-$ $3.19(\mathrm{~m}, 5 \mathrm{H}), 4.86(\mathrm{~s}, 1 \mathrm{H}), 5.75(\mathrm{~s}, 1 \mathrm{H}), 6.90-7.04(\mathrm{~m}, 19 \mathrm{H})$. HRMS (MALDI-TOF): $m / z$ calcd $\left[\mathrm{M}+\mathrm{Na}^{+}\right]$1061.7621; found 1061.7802.

\section{Preparation of cis-TPE-L-DGlu and trans-TPE-L-DGlu}

The same procedure as that of TPE-L-Glu was used for cis-TPE-L-DGlu and trans-TPE-L-DGlu. The characterization of cis-TPE-L-DGlu: ${ }^{1} \mathrm{H} \mathrm{NMR}\left(400 \mathrm{MHz}, \mathrm{CDCl}_{3}\right) \delta(\mathrm{ppm}): 0.86(\mathrm{t}, J=6.2 \mathrm{~Hz}, 12 \mathrm{H})$, $1.23(\mathrm{~s}, 120 \mathrm{H}), 1.35(\mathrm{t}, J=7.3 \mathrm{~Hz}, 8 \mathrm{H}), 1.42(\mathrm{~s}, 8 \mathrm{H}), 3.08-3.21$ $(\mathrm{m}, 12 \mathrm{H}), 6.82(\mathrm{~d}, J=8.5 \mathrm{~Hz}, 4 \mathrm{H}), 6.97(\mathrm{~d}, J=3.7 \mathrm{~Hz}, 4 \mathrm{H}), 7.00-7.05$ (m, 10H). HRMS (MALDI-TOF): $m / z$ calcd $\left[\mathrm{M}+\mathrm{Na}^{+}\right]$1768.3780; found 1768.3894. trans-TPE-L-DGlu: ${ }^{1} \mathrm{H}$ NMR (400 $\left.\mathrm{MHz}, \mathrm{CDCl}_{3}\right) \delta$ (ppm): 0.86 (t, $J=6.6 \mathrm{~Hz}, 12 \mathrm{H}), 1.24(\mathrm{~s}, 120 \mathrm{H}), 1.37-1.45(\mathrm{~m}, 16 \mathrm{H})$, $1.68(\mathrm{~d}, J=10.3 \mathrm{~Hz}, 4 \mathrm{H}), 3.11-3.17(\mathrm{~m}, 4 \mathrm{H}), 6.86(\mathrm{~d}, J=8.3 \mathrm{~Hz}, 4 \mathrm{H})$, 6.98 (d, $J=3.6 \mathrm{~Hz}, 4 \mathrm{H}), 7.01-7.10$ (m, 10H). HRMS (MALDI-TOF): $\mathrm{m} / \mathrm{z}$ calcd $\left[\mathrm{M}+\mathrm{Na}^{+}\right]$1768.3780; found 1768.3960 .

\section{Preparation of samples for optical measurements}

Several stock solutions of the compounds were first prepared in THF $(0.20 \mathrm{mM})$. Then, $10 \mu \mathrm{L}$ of the stock solution was transferred to $2 \mathrm{~mL} \mathrm{THF} /$ water mixture to afford the test solutions at the concentration of $10 \mu \mathrm{M}$. The optical measurements were then performed after $2 \mathrm{~h}$.

\section{Preparation of samples for SEM}

Different THF/water mixtures of TPE-L-Glu, TPE-D-Glu, cis-TPEL-DGlu and trans-TPE-L-DGlu with concentrations of $10 \mu \mathrm{M}$ were prepared. Then, $10 \mu \mathrm{L}$ of the solutions was dropped onto the surface of Si wafers, which were dried in vacuum after $2 \mathrm{~h}$. The as-prepared samples were characterized by SEM.

\section{Results and discussions}

\section{Synthesis of chiral AIEgens}

Compounds 1, cis- and trans-2, L- and D-5 were prepared according to previously reported procedures. ${ }^{11}$ The initial compounds first 

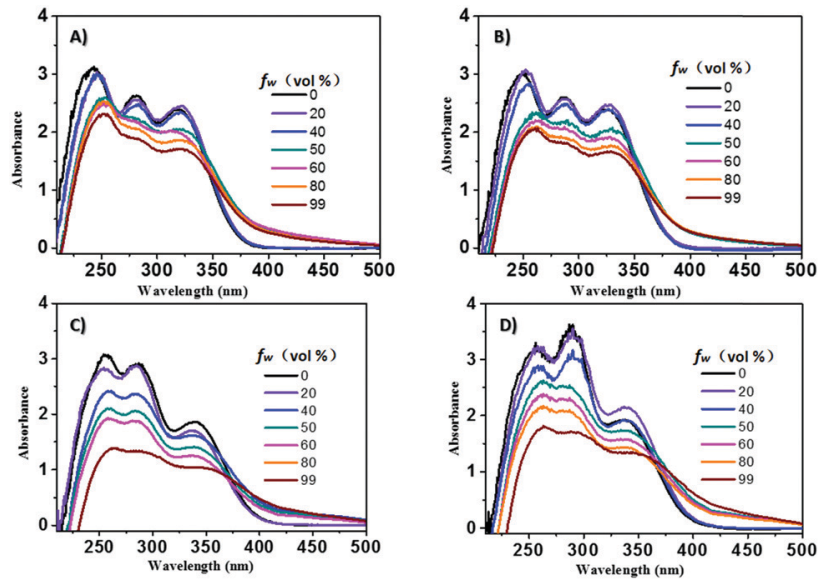

Fig. 1 UV-vis absorption spectra of (A) TPE-L-Glu, (B) TPE-D-Glu, (C) cis-TPE-L-DGlu and (D) trans-TPE-L-DGlu in THF/water mixture with different $f_{\mathrm{w}}$. Concentration: $1 \times 10^{-5} \mathrm{M}$.

reacted with thiophosgene to obtain mono- or di-isothiocyanato compounds 3 and cis- and trans-4. These intermediates then reacted with chiral glutamic derivatives (compound $\mathrm{L}^{-}$or $\mathrm{D}-5$ ) to afford the four desired compounds. All the compounds were confirmed by NMR and HRMS (see ESI $\dagger$ ).

\section{Optical properties}

The UV-vis spectra of these compounds were first obtained in a THF/water mixture, in which THF acted as a good solvent and water acted as a poor solvent. As shown in Fig. 1, the four compounds, TPE-L-Glu, TPE-D-Glu, cis-TPE-L-DGlu and transTPE-L-DGlu, exhibited similar absorption spectra with three absorption peaks located at about 250, 285 and $340 \mathrm{~nm}$, respectively, which could result from the $\pi-\pi^{*}$ conjugation of the TPE cores. When $f_{\mathrm{w}}$ was increased in the mixture, the decreased absorbance and spectral tails in the long wavelength region were clear probably due to the formation of aggregates, ${ }^{12}$ and the observed red-shift indicated that J-aggregate could be formed in the mixture. ${ }^{13}$ Interestingly, the absorption spectra of TPE-D-Glu displayed a small red-shift of $7 \mathrm{~nm}$ compared to TPE-L-Glu, which might be ascribed to the different sizes of the formed nanoparticles.

Next, we investigated their CD spectra. As shown in Fig. 2A, the CD data of the mono-substituted compounds demonstrated that both compounds were CD silent in THF. However, the aggregation-induced CD (AICD) signals could be observed with an increase in $f_{\mathrm{w}}$ of the mixed solvents. The two enantiomers exhibited slightly deflected mirror-imaged AICD signals, whose signals were consistent with their absorption data. Moreover, we found that the AICD signals apparently enhanced with higher $f_{\mathrm{w}}$, and could reach the maximum when $f_{\mathrm{w}}$ was at $99 \%$.

As depicted in Fig. 2B and C, cis-TPE-L-DGlu presented a very weak signal at $290 \mathrm{~nm}$ in THF, while trans-TPE-L-DGlu had almost no signal at the same condition. The different AICD signals in THF between two isomers could result from the formation of the intramolecular hydrogen bond of the cis-isomer. Moreover, obvious aggregation-induced Cotton effects were observed with
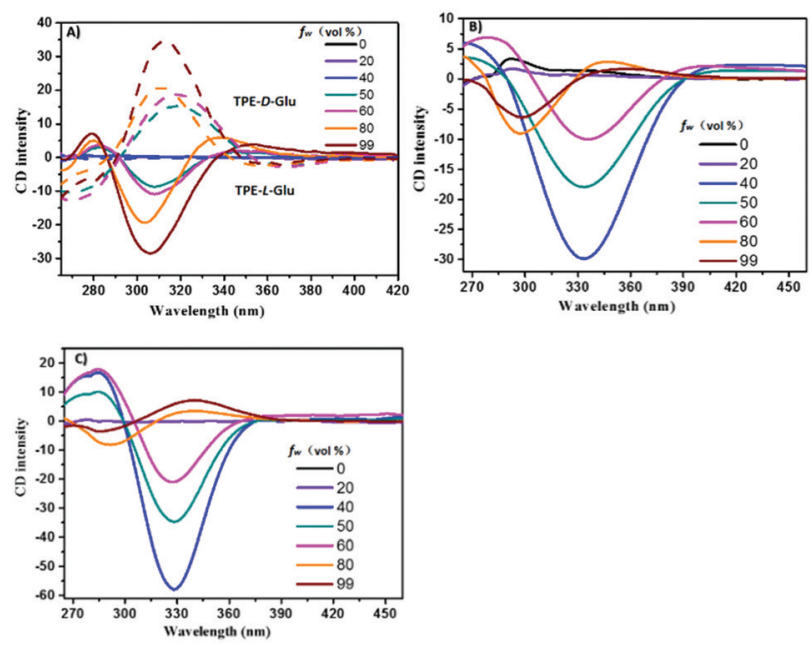

Fig. 2 CD spectra of (A) TPE-D-Glu and TPE-L-Glu, (B) cis-TPE-L-DGlu, (C) trans-TPE-L-DGlu in THF/water mixtures with different $f_{\mathrm{w}}$. Solution concentration $=1 \times 10^{-5} \mathrm{M}$.

increased $f_{\mathrm{w}}$. The negative signals at $330 \mathrm{~nm}$ of the isomers were highest when $f_{\mathrm{w}}$ was at $40 \%$, i.e., the CD signal of trans-isomer was about twice than that of cis-isomer probably due to the different hydrogen bonds of the inter- and intra-forms. However, the negative signals decreased and displayed a slight red-shift when water was present in the mixture until $f_{\mathrm{w}}$ was up to $60 \%$. Furthermore, the negative signals at about $296 \mathrm{~nm}$ and positive signals at about $350 \mathrm{~nm}$ of cis-TPE-L-DGlu were detected when more water was added. The trans-isomer had similar negative and positive signals, which were related to those of the cis-isomer. All the above data indicated that the point chirality of the glutamic moiety could transfer to the TPE part in aggregates.

For the two di-substituted isomers, trans-cis isomerization could theoretically occur in the excited state. However, when the size of substituents or the interactions between the substituents increase, the trans-cis isomerization becomes much more difficult, according to the previous reported works. ${ }^{11 b, 14}$ The fluorescence spectra of mono- and di-substituted compounds are shown in Fig. 3. As predicted, the four TPE-containing
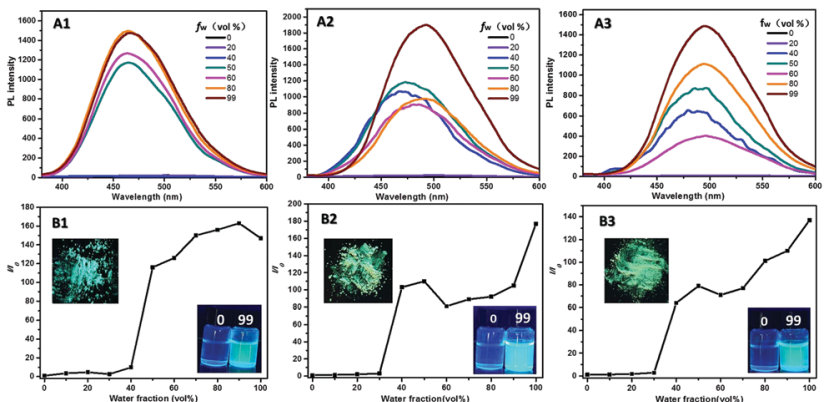

Fig. 3 Fluorescent spectra of TPE-L-Glu, cis-TPE-L-DGlu and trans-TPEL-DGlu in THF/water mixed solvents with different $f_{\mathrm{w}}$ (A1-A3); plot of $I / I_{0}$ values versus $f_{\mathrm{w}}$ (B1-B3), where $I_{0}$ represents the emission intensity in THF. Concentration: $1 \times 10^{-5} \mathrm{M}$; excitation wavelength: $340 \mathrm{~nm}$. Inset: Photographs of TPE-L-Glu, cis-TPE-L-DGlu and trans-TPE-L-DGlu in solid and THF/water mixtures with 0 and $99 \% f_{\mathrm{w}}$ under $365 \mathrm{~nm}$ UV lamp. 
compounds were AIE-active. Their fluorescence intensities were relatively weak when $f_{\mathrm{w}}$ was less than $40 \%$ in the mixed solvents and enhanced rapidly with the addition of more water due to the formation of aggregates. The highest fluorescent intensities could increase to 164, 176 and 138 times for TPE-L-Glu, cis-TPE-L-DGlu and trans-TPE-L-DGlu, respectively. Both the aggregates in $99 \% f_{\mathrm{w}}$ mixtures and their solids displayed high green emission. Moreover, the emission peaks shifted to longer wavelengths with increase in $f_{\mathrm{w}}$, which further indicated the formation of $\mathrm{J}$ aggregates.

The aggregates exhibited strong fluorescence and obvious AICD signals, which inspired us to further investigate their CPL properties. As shown in Fig. 4A, TPE-L-Glu and TPE-D-Glu exhibited mirrored AICPL spectra in the region from 400 to $600 \mathrm{~nm}$ when $f_{\mathrm{w}}$ was higher than $50 \%$. The highest AICPL signals decreased and red-shifted when more water was added to the mixed solvents. The CPL dissymmetry factor, $g_{\text {lum }}$, could reach 0.021 and -0.019 for TPE-L-Glu and TPE-D-Glu, respectively. Interestingly, the original AICPL signals of cis-TPE-L-DGlu and trans-TPE-L-DGlu exhibited opposite signs compared with TPE-L-Glu although they had the same chiral L-glutamic moiety, which could be attributed to the different intermolecular noncovalent interactions. ${ }^{6 a, 15}$ The two di-substituted compounds possessed similar AICPL spectra with the highest signal at $60 \% f_{\mathrm{w}}$, and their AICPL signals could reverse when $f_{\mathrm{w}}$ was higher than $80 \%$, whose $g_{\text {lum }}$ values changed from -0.007 to 0.003 for cis-isomer, and from -0.008 to 0.002 for the trans-isomer, respectively. All the data indicated that the AICPL properties of these TPE derivatives could be adjusted by both the chirality of chiral source (L or D-stereoisomers) and the number of introduced substituents (mono- or di-substituted). The strength of the CPL signals could be tuned by changing $f_{\mathrm{w}}$ in the mixed solvents.
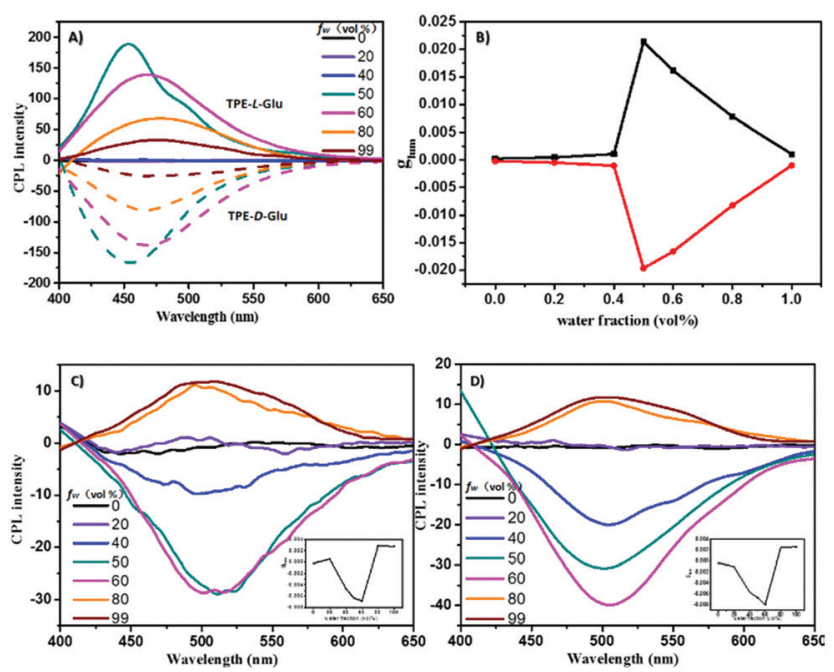

Fig. 4 CPL spectra of (A) TPE-L-Glu and TPE-D-Glu, (C) cis-TPE-L-DGlu, (D) trans-TPE-L-DGlu in THF/water mixed solvents. Concentration: $1 \times 10^{-5} \mathrm{M}$; excitation wavelength: $340 \mathrm{~nm}$. (B) $g_{\text {lum }}$ versus $f_{\mathrm{w}}$ of TPE-LGlu and TPE-D-Glu. Inset: $g_{\text {lum }}$ versus $f_{\mathrm{w}}$ of cis-TPE-L-DGlu and transTPE-L-DGlu.

\section{The morphologies of the aggregates}

According to the above optical data, all the compounds displayed tunable aggregation-induced optically active properties by changing $f_{\mathrm{w}}$ of the mixed solvents, which stimulated us to investigate the relation between optical activities and supramolecular morphologies of the self-assembled aggregates. Moreover, to demonstrate the intermolecular interactions of the compounds even in THF, we obtained the SEM images of formed nanostructures after THF was volatilized. As shown in Fig. 5, the morphologies of formed self-assemblies were obviously different when the $f_{\mathrm{w}}$ of the mixed solvents was changed. For the enantiotopic mono-substituted compounds, the SEM images of the compounds in THF $(10 \mu \mathrm{M})$ showed the formation of similar nanofibers, which further showed intermolecular interactions even in the molecular state. Thicker nanofibers were detected when $f_{\mathrm{w}}$ was increased to $40 \%$ due to the formation of aggregates. Moreover, helical nanofibers formed when $50 \% f_{\mathrm{w}}$ was in the mixed solvents, which L-enantiomer produced left-handed twist nanofibers and D-enantiomer gave the right-handed ones. However, irregular nanoparticles formed after more water was added. The different morphologies of formed nanostructures could lead to the changes in the AICPL intensities. For cis- and trans-isomeric compounds, different irregular nanoparticles were detected in the mixed solvents probably due to the different intra- or intermolecular interactions. cis-TPE-L-DGlu with two L-glutamic moieties located at the same side experience intramolecular interactions that could lead to form nanoparticles to reduce energy. ${ }^{16}$ However, trans-TPE-L-DGlu with two substituents on the opposite sides could undergo intermolecular weak interactions and self-assembled in side-by-side formation to generate nanoribbons. ${ }^{17}$ The different noncovalent interactions resulted in the formation of diverse nanostructures and further affected the intensities of the AICPL signals of the two isomers. Note that the trans-one gave higher signals compared to the cis-one.

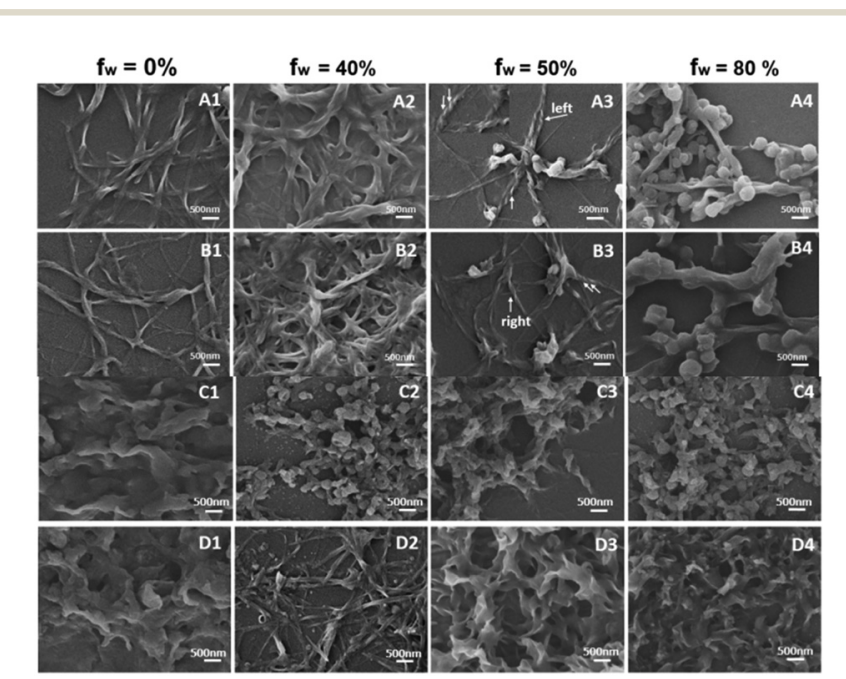

Fig. 5 SEM images of TPE-L-Glu (A1-A4), TPE-D-Glu (B1-B4), cis-TPE-LDGlu (C1-C4), trans-TPE-L-DGlu (D1-D4) obtained from THF/water mixed solvents at different $f_{\mathrm{w}}$. (A1-D1) 10/0; (A2-D2) 6/4; (A3-D3) 5/5; (A4-D4) 1/9. Concentration: $1 \times 10^{-5} \mathrm{M}$. 
The SEM images of the self-assemblies indicate that AICPL signals could be affected by the morphologies of formed microstructures, which the distinguishing formed nanostructures should originally ascribe to the different intermolecular interactions between the mono- and di-substituted AIEgens.

\section{Conclusions}

In conclusion, we designed and synthesized four chiral AIEgens containing TPE and one or two chiral glutamic moieties that were connected by thiourea. All the compounds exhibited aggregation-induced optical activities in a THF/water mixture. The enantiotopic mono-substituted compounds gave mirrorimaged AICPL signals, whose $\left|g_{\text {lum }}\right|$ value could reach 0.02. The di-substituted isomers showed opposed original AICPL signals compared with mono-substituted isomers although they had the same chiral glutamic moiety. cis- and trans-isomers displayed similar AICPL properties, whose signs of AICPL signals reversed when $f_{\mathrm{w}}$ was more than $80 \%$. The SEM images of the selfassemblies indicated that AICPL properties could be related to the number of substituents in molecules and the formed selfassembled microstructures.

\section{Conflicts of interest}

There are no conflicts to declare.

\section{Acknowledgements}

We gratefully acknowledge for financial support from the National Natural Science Foundation of China (No. 21702180), Jiangsu Provincial Nature Science Foundation (SBK2016021885), the Top-notch Academic Programs Project of Jiangsu Higher Education Institutions, and the Priority Academic Program Development of Jiangsu Higher Education Institutions.

\section{Notes and references}

1 (a) Y. Ying, R. C. da Costa, D.-M. Smilgies, A. J. Campbell and M. J. Fuchter, Adv. Mater., 2013, 25, 2624; (b) M. Li, S.-H. Li, D. Zhang, M. Cai, L. Duan, M.-K. Fung and C.-F. Chen, Angew. Chem., Int. Ed., 2018, 57, 2889; (c) J. R. Brandt, X. Wang, Y. Yang, A. J. Campbell and M. J. Fuchter, J. Am. Chem. Soc., 2016, 138, 9743; (d) W. Li, Z. J. Coppens, L. V. Besteiro, W. Wang, A. O. Govorov and J. Valentine, Nat. Commun., 2015, 6, 8379; (e) J. Kumar, T. Nakashima, H. Tsumatori and T. Kawai, J. Phys. Chem. Lett., 2014, 5, 316; $(f)$ H. Ruthanne, E. J. Swain, N. I. Hammer, D. Venkataraman and M. D. Barnes, Science, 2006, 314, 1437; ( $g$ ) C. Chen, J. Chen, T. Wang and M. Liu, ACS Appl. Mater. Interfaces, 2016, 8, 30608; (h) M. Shimada, Y. Yamanoi, T. Ohto, S.-T. Pham, R. Yamada, H. Tada, K. Omoto, S. Tashiro, M. Shionoya, M. Hattori, K. Jimura, S. Hayashi, H. Koike, M. Iwamura, K. Nozaki and H. Nishihara, J. Am. Chem. Soc., 2017, 139, 11214; (i) F. Song, Z. Xu, Q. Zhang, Z. Zhao, H. Zhang, W. Zhao, Z. Qiu, C. Qi,
H. Zhang, H. H. Y. Sung, I. D. Williams, J. W. Y. Lam, Z. Zhao, A. Qin, D. Ma and B. Z. Tang, Adv. Funct. Mater., 2018, 28, 1800051.

2 (a) K. Nakamura, S. Furumi, M. Takeuchi, T. Shibuya and K. Tanaka, J. Am. Chem. Soc., 2014, 136, 5555; (b) T. Wu and P. Bouř, Chem. Commun., 2018, 54, 1790; (c) Y. Wang, X. Li, L. Yang, W. Y. Sun, C. Zhu and Y. Cheng, Mater. Chem. Front. , 2018, 2, 554; (d) Y. Nagata, M. Uno and M. Suginome, Angew. Chem., Int. Ed., 2016, 55, 7126; (e) J. Zhang, Q. Liu, W. Wu, J. Peng, H. Zhang, F. Song, B. He, X. Wang, H. H.-Y. Sung, M. Chen, B. S. Li, S. H. Liu, J. W. Y. Lam and B. Z. Tang, ACS Nano, 2019, 13, 3618; $(f)$ B. Zhao, K. Pan and J. Deng, Macromolecules, 2018, 51, 7104; $(g)$ Y. Chen, X. Li, N. Li, Y. Quan, Y. Cheng and Y. Tang, Mater. Chem. Front., 2019, 3, 867; (h) N. Zhao, W. Gao, M. Zhang, J. Yang, X. Zheng, Y. Li, R. Cui, W. Yin and N. Li, Mater. Chem. Front., 2019, 3, 1613.

3 (a) W. Z. Yuan, P. Lu, S. Chen, J. W. Y. Lam, Z. Wang, Y. Liu, H. S. Kwok, Y. Ma and B. Z. Tang, Adv. Mater., 2010, 22, 2159; (b) S. W. Thomas, G. D. Joly and T. M. Swager, Chem. Rev., 2007, 107, 1339; (c) J. Liang, B. Z. Tang and B. Liu, Chem. Soc. Rev., 2015, 44, 2798; (d) A. S. Klymchenko, Acc. Chem. Res., 2017, 50, 366.

4 (a) J. D. Luo, Z. L. Xie and B. Z. Tang, Chem. Commun., 2001, 1740; (b) J. Mei, N. L. C. Leung, R. T. K. Kwok, J. W. Y. Lam and B. Z. Tang, Chem. Rev., 2015, 115, 11718.

5 J. Liu, H. Su, L. Meng, Y. Zhao, C. Deng, J. C. Y. Ng, P. Lu, M. Faisal, J. W. Y. Lam, X. Huang, H. Wu, K. S. Wong and B. Z. Tang, Chem. Sci., 2012, 3, 2737.

6 (a) H. Li, J. Cheng, Y. Zhao, J. W. Y. Lam, K. S. Wong, H. Wu, B. S. Li and B. Z. Tang, Mater. Horiz., 2014, 1, 518; (b) X. Liu, J. Jiao, X. Jiang, J. Li, Y. Cheng and C. Zhu, J. Mater. Chem. C, 2013, 1, 4713; (c) S. Zhang, Y. Wang, F. Meng, C. Dai, Y. Cheng and C. Zhu, Chem. Commun., 2015, 51, 9014; (d) Q. Liu, Q. Xia, S. Wang, B. S. Li and B. Z. Tang, J. Mater. Chem. C, 2018, 6, 4807; (e) J. Roose, B. Z. Tang and K. S. Wong, Small, 2016, 12, 6495; $(f)$ G. Huang, R. Wen, Z. Wang, B. S. Li and B. Z. Tang, Mater. Chem. Front., 2018, 2, 1884.

7 (a) E. M. Sánchez-Carnerero, A. R. Agarrabeitia, F. Moreno, B. L. Maroto, G. Muller, M. J. Ortiz and S. de la Moya, Chem. Eur. J., 2015, 21, 13488; (b) Y. Zhang, D. Yang, J. Han, J. Zhou, Q. Jin, M. Liu and P. Duan, Langmuir, 2018, 34, 5821; (c) T. Goto, Y. Okazaki, M. Ueki, Y. Kuwahara, M. Takafuji, R. Oda and H. Ihara, Angew. Chem., Int. Ed., 2017, 56, 2989; (d) E. Yashima, N. Ousaka, D. Taura, K. Shimomura, T. Ikai and K. Maeda, Chem. Rev., 2016, 116, 13752; (e) D. Niu, Y. Jiang, L. Ji, G. Ouyang and M. Liu, Angew. Chem., Int. Ed., 2019, 58, 5946.

8 (a) H. Rhee, I. Eom, S.-H. Ahn and M. Cho, Chem. Soc. Rev., 2012, 41, 4457; (b) F. S. Richardson, Chem. Rev., 1979, 79, 17. 9 (a) J. Wang, J. Mei, R. R. Hu, J. Z. Sun, A. J. Qin and B. Z. Tang, J. Am. Chem. Soc., 2012, 134, 9956; (b) C.-J. Zhang, G. Feng, S. Xu, Z. Zhu, X. Lu, J. Wu and B. Liu, Angew. Chem., Int. Ed., 2016, 55, 6192; (c) X. F. Fang, Y.-M. Zhang, K. Chang, Z. Liu, X. Su, H. Chen, S. X.-A. Zhang, Y. Liu and C. Wu, Chem. Mater., 2016, 28, 6628. 
10 (a) Q. Ye, D. Zhu, H. Zhang, X. Lu and Q. Lu, J. Mater. Chem. C, 2015, 3, 6997; (b) B. S. Li, R. Wen, S. Xue, L. Shi, Z. Tang, Z. Wang and B. Z. Tang, Mater. Chem. Front., 2017, 1, 646; (c) H. Li, B. S. Li and B. Z. Tang, Chem. - Asian J., 2019, 14, 674; (d) J. Han, J. You, X. Li, P. Duan and M. Liu, Adv. Mater., 2017, 29, 1606503; (e) S. Zhang, Y. Sheng, G. Wei, Y. Quan, Y. Cheng and C. Zhu, Polym. Chem., 2015, 6, 2416; $(f)$ J. Li, C. Yang, C. Huang, Y. Wan and W.-Y. Lai, Tetrahedron Lett., 2016, 57, 1256.

11 (a) M. Luo, X. Zhou, Z. Chi, S. Liu, Y. Zhang and J. Xu, Dyes Pigm., 2014, 101, 74; (b) H.-Q. Peng, X. Zheng, T. Han, R. T. K. Kwok, J. W. Y. Lam, X. Huang and B. Z. Tang, J. Am. Chem. Soc., 2017, 139, 10150; (c) T. Matsumoto, F. Yamada and T. Kurosaki, Macromolecules, 1997, 12, 3547; (d) Y. Li, T. Wang and M. Liu, Soft Matter, 2007, 3, 1312.

12 (a) N. J. Hestand and F. C. Spano, Acc. Chem. Res., 2017, 50, 341; (b) C. Dai, D. Yang, W. Zhang, B. Bao, Y. Cheng and L. Wang, Polym. Chem., 2015, 6, 3962.

13 (a) M. E. Ziffer, S. B. Jo, Y. Liu, H. Zhong, J. C. Mohammed, J. S. Harrison, A. K.-Y. Jen and D. S. Ginger, J. Phys. Chem. C, 2018, 122, 18860; (b) V. Grande, B. Soberats, S. Herbst, V. Stepanenko and F. Würthner, Chem. Sci., 2018, 9, 6904; (c) S. B. Anantharaman, T. Stöferle, F. A. Nüesch, R. F. Mahrt and J. Heier, Adv. Funct. Mater., 2019, 29, 1806997.
14 (a) J. Li, X. Peng, C. Huang, Q. Qi, W.-Y. Lai and W. Huang, Polym. Chem., 2018, 9, 5278; (b) J. Li, C. Yang, X. Peng, Y. Chen, Q. Qi, X. Luo, W.-Y. Lai and W. Huang, J. Mater. Chem. C, 2018, 6, 19; (c) X. Fang, Y.-M. Zhang, K. Chang, Z. Liu, X. Su, H. Chen, S. X.-A. Zhang, Y. Liu and C. Wu, Chem. Mater., 2016, 28, 6628.

15 (a) H. Li, J. Cheng, H. Deng, E. Zhao, B. Shen, J. W. Y. Lam, K. S. Wong, H. Wu, B. S. Li and B. Z. Tang, J. Mater. Chem. C, 2015, 3, 2399; (b) H. Li, X. Zheng, H. Su, J. W. Y. Lam, K. S. Wong, S. Xue, X. Huang, X. Huang, B. S. Li and B. Z. Tang, Sci. Rep., 2016, 6, 19277.

16 (a) I. H. Nayyar, E. R. Batista, S. Tretiak, A. Saxena, D. L. Smith and R. L. Martin, J. Polym. Sci., Part B: Polym. Phys., 2013, 51, 935; (b) A. Declemy, C. Rulliere and P. Kottis, Chem. Phys. Lett., 2017, 101, 401; (c) Y.-Z. Zheng, Y. Zhou, Q. Liang, D.-F. Chen, R. Guo, C.-L. Xiong, X.-J. Xu, Z.-N. Zhang and Z.-J. Huang, Dyes Pigm., 2017, 141, 179.

17 (a) H. Zhang, C. Guo, X. Wang, J. Xu, X. He, Y. Liu, X. Liu, H. Huang and J. Sun, Cryst. Growth Des., 2013, 13, 679; (b) Z. Wang, Y. Gong, L. Zhang, C. Jing, F. Gao, S. Zhang and H. Li, Chem. Eng. J., 2018, 342, 238; (c) C. Chen, T. Wang, Y. Fu and M. Liu, Chem. Commun., 2016, 52, 1381. 